De Clercq, Dirk (2019) Getting creative with resources : how resilience, task interdependence, and emotion sharing mitigate the damage of employee role ambiguity. Journal of Applied Behavioral Science, 55(3), pp. 369-391. Copyright (C) 2019(The Author). DOI: https://doi.org/10.1177/0021886319853803. 
Getting creative with resources: How resilience, task interdependence, and emotion sharing mitigate the damage of employee role ambiguity

\section{Dirk De Clercq}

Paper accepted for The Journal of Applied Behavioral Science

May 2, 2019 


\title{
Getting creative with resources: How resilience, task interdependence, and emotion sharing mitigate the damage of employee role ambiguity
}

\begin{abstract}
This article investigates how employees' experience of role ambiguity might inhibit their creative behavior but also how this harmful effect might be buffered by employees' access to relevant individual (resilience), job task (task interdependence), and relational (emotion sharing) resources. The uncertainty resulting from information deficiencies about job responsibilities diminishes in the presence of these resources, such that employees might be less likely to react to this resource-draining work condition by exhibiting a reluctance to develop change-invoking ideas for organizational improvement. Using survey data from employees in a large organization that operates in the renewable energy sector, this study shows that role ambiguity diminishes creative behavior, but this detrimental effect is subdued with higher levels of resilience, task interdependence, and emotion sharing. As this study shows, organizations that cannot avoid ambiguity in their employees' work roles should adopt efforts to offset the associated challenge of thwarted creative behaviors with pertinent resources.
\end{abstract}

Keywords: role ambiguity; creativity; resilience; task interdependence; emotion sharing; conservation of resources theory 


\section{Introduction}

Employees can contribute significantly to their organization's competitive advantage through their creative behaviors (Chen \& Kaufmann, 2008; Tierney, Farmer, \& Graen, 1999), defined as their propensity to develop change-invoking ideas that can improve the current organizational situation (Amabile, 1988; Oldham \& Cummings, 1996; Shalley \& Gilson, 2004). Creative behaviors are beneficial not only to the organization but also to employees themselves, in that these behaviors can spur their individual learning (Parboteeah, Hoegl, \& Muethel, 2015) and satisfaction (Kim, Hon, \& Grant, 2009). Despite these positive outcomes, creating changeinvoking ideas for organizational improvement can be challenging for employees, because others may view their activities as disruptive or threatening to their current privileges (Sutton \& Hargadon, 1996; Zhou \& George, 2001). For example, when employees suggest novel solutions to organizational problems, other organizational members may demonstrate strong resistance, if they feel threatened by the associated changes (Buchanan \& Badham, 1999; Yuan \& Woodman, 2010).

The possible resistance that comes with disruptive creative behaviors can be particularly problematic in the presence of unfavorable work conditions that discourage such behaviors. For example, employees' propensity to go out of their way to generate novel ideas might be thwarted by unsupportive leadership (Zhou \& Pan, 2015), excessive workloads (Kark, Van Dijk, \& Vashdi, 2018), perceptions of organizational unfairness (Shalley \& Gilson, 2004), or insufficient decision power (Si \& Wei, 2012). An additional, rarely studied inhibitor of employees' creative behaviors also might stem from incomplete information available to them about their job responsibilities — a work condition that fuels uncertainty about their organizational functioning and career prospects (Chen, Lin, \& Lien, 2011; Schmidt, Roesler, Kusserow, \& Rau, 2014; 
Trépanier, Fernet, \& Austin, 2013). The negative feelings that employees experience due to such role ambiguity have been shown to diminish the likelihood that they engage in productive, performance-enhancing behaviors (Showail, McClean Parks, \& Smith, 2013; Zhou, Martinez, Ferreira, \& Rodrigues, 2016), but previous research has not detailed the potentially harmful effects of role ambiguity on the development of change-invoking ideas for organizational improvement, nor investigated how this process might be contained (Coelho, Augusto, \& Lages, 2011; Groza, Locander, \& Howlett, 2016).

To theorize about why role ambiguity might inhibit creative behaviors, and the circumstances in which this process is less likely to initiate, we suggest that incomplete job descriptions may reduce employees' ability and motivation to make time for such effortful behaviors (Kahn, Wolfe, Quinn, Snoek, \& Rosenthal, 1964; Schmidt et al., 2014). When employees suffer from information deficiencies in relation to their job duties, their ability to contribute effectively to their organization's success through creative activities might be undermined, along with their intrinsic motivation to perform such activities (Eatough, Chang, Miloslavic, \& Johnson, 2011; Ryan \& Deci, 2000). In turn, we suggest that the escalation of role ambiguity into diminished creativity might be avoided, to the extent that employees have access to energy-enhancing resources that spur their ability or desire to generate change-invoking ideas for the benefit of their organization (Quinn, Spreitzer, \& Lam, 2012). Such resources might be particularly useful for employees who operate in internal environments that are so complex that the organization cannot realistically clarify, for each and every employee, what their specific responsibilities entail (Elovainio \& Kivimäki, 2001; Kahn et al., 1964).

Our theoretical arguments about the negative relationship between role ambiguity and creative behavior, and the circumstances in which role ambiguity is less likely to translate into 
reduced creativity, are anchored in conservation of resources (COR) theory (Hobfoll, 1989, 2001). This theory postulates that resource-draining work conditions reduce employees' energy levels, so they turn away from productive work activities, but their access to relevant resources can attenuate or buffer this process (Abbas, Raja, Darr, \& Bouckenooghe, 2014; Hobfoll \& Shirom, 2000). First, when employees believe that they receive insufficient information about their job duties, the energy depletion they experience may compromise their efforts to generate change-invoking ideas (Coelho et al., 2011; Eatough et al., 2011). Second, this negative relationship between role ambiguity and creative behavior should be less prominent to the extent that employees (1) are resilient or easily bounce back from challenging situations, (2) operate in task environments marked by high levels of task interdependence, and (3) are able to share their personal emotions with organizational peers. Resilience is a personal resource that enables employees to cope successfully with ambiguous work situations, because they see such situations as opportunities to learn (Youssef \& Luthans, 2007). Task interdependence is a task-related resource that reflects interconnectedness in the work activities undertaken by different organizational members, such that employees can draw from one another's expertise and support and thus find time for creative behaviors, despite the presence of role ambiguity (Van der Vegt, Emans, \& Van de Vliert, 2002). Finally, emotion sharing is a relational resource that pertains to the extent to which employees openly express their emotions with peers, including both positive and negative feelings about their organizational functioning (Stephens, Heaphy, Carmeli, Spreitzer, \& Dutton, 2013).

We propose that these three resources, conceptualized herein as moderators, provide employees with the energy they need to engage in creative behaviors, despite the presence of resource-depleting role ambiguity (Zhou et al., 2016). All three resources are similar, in the sense 
that they infuse employees with positive energy that spurs their ability and motivation to maintain some level of creativity, even when they suffer from information shortages in their job descriptions (Amabile, 1996; Quinn et al., 2012). While each moderator provides a source of positive energy, they operate at different levels: Resilience evokes positive energy that employees possess internally (Luthans, 2002); task interdependence implies positive energy stemming from the type of work undertaken, as manifest in the interrelatedness of employees' job tasks (Wageman \& Baker, 1997); and emotion sharing entails positive energy from close social exchanges with colleagues (Stephens et al., 2013). By addressing these three matching but distinct contingency factors, we obtain consistent, encompassing insights into how employees' resource access may buffer against their propensity to avoid creative behaviors in the presence of unclear job descriptions (Hobfoll \& Shirom, 2000).

In short, we extend extant research by theorizing how three resources-resilience, task interdependence, and emotion sharing — diminish the likelihood that employees refrain from generating change-invoking ideas for organizational improvement in response to role ambiguity. In so doing, we address calls to apply contingency approaches to explain creativity in the workplace (Aleksic, Mihelic, Cerne, \& Skerlavaj, 2017; De Clercq, Rahman, \& Belausteguigoitia, 2017), including those in which employees suffer from job-related information deficiencies (Bogilovic, Cerne, \& Skerlavaj, 2017). We postulate that employees' negative responses to ambiguous work roles, in the form of a reluctance to carry out creative activities, should be countered by these three resources, which thus far rarely have been explored in relation to employees' experience of role stress.

\section{Theoretical background and hypotheses}

\section{Proposed framework}


Creative behaviors generate new ideas to provide solutions for organizational problems and enhance organizational effectiveness (Oldham \& Cummings, 1996). They are instrumental to both employees and their organizations. For example, finding novel solutions to problem situations can increase employees' work motivation (Kim et al., 2009), stimulate their career prospects (Seibert, Kraimer, \& Crant, 2001), and enhance their job performance (Gong, Huang, \& Farh, 2009). Generating novel solutions to problems also can stimulate organizational learning (Argyris \& Schon, 1978) and positive organizational change (Maimone \& Sinclair, 2014).

Despite these beneficial effects, change-invoking creative behaviors, such as those that focus on problem areas, may be challenging, because other organizational members could disagree about the effectiveness of the proposed novel solutions (Van Dijk \& Van Dick, 2009; Zhou \& George, 2001) or resist solutions that create some perceived threat of reputation loss, when the resolved problems are their responsibility (Buchanan \& Badham, 1999; Kotter \& Schlesinger, 1979; Yuan \& Woodman, 2010). In light of these challenges, it is important to understand when employees might be reluctant to generate new ideas for organizational improvement, particularly when they encounter adverse work conditions that undermine their ability or motivation to undertake these activities.

We focus in particular on role ambiguity, which captures the extent to which employees receive unclear information about their work roles (Fried \& Tiegs, 1995; Zhang, Tsingan, \& Zhang, 2013). Employees tend to feel hampered in the execution of their daily job tasks when they believe that there are significant information deficiencies, in terms of what is expected of them (Chen, Takeuchi, \& Shum, 2013; Trépanier et al., 2013). Such role ambiguity is energy draining because it curtails employees' anticipated job performance and career development (Eatough et al, 2011; Singh, Suar, \& Leiter, 2012; Zhou et al., 2016) and accordingly might pose 
a potential threat to their propensity to undertake energy-consuming, creative activities.

As noted, we draw from COR theory to examine the relationship between employees'

role ambiguity and the likelihood that they avoid creative behaviors, as well as how this harmful effect might be mitigated by their access to relevant resources (Abbas et al., 2014; Hobfoll, 2001). The three selected resources that we consider (resilience, task interdependence, and emotion sharing) each can help counter the uncertainty that employees experience in the presence of job-related information shortages (Kahn et al., 1964; Schmidt et al., 2014) and thus mitigate the likelihood that they avoid productive creative behaviors in response to role ambiguity. We summarize the theoretical framework in Figure 1, and we outline its constitutive hypotheses next.

\section{[Insert Figure 1 about here]}

\section{Role ambiguity and creative behavior}

As a baseline hypothesis, we predict that employees' propensity to undertake creative behaviors is lower to the extent that they experience significant ambiguity in their work roles. When employees feel uncertain about their job responsibilities, they suffer frustration related to executing their job tasks (Cordes \& Dougherty, 1993; Schmidt et al., 2014). The associated energy depletion in turn might compromise their ability to add to their organization's success through productive work activities, such as generating novel ideas (Amabile, 1996; Hobfoll, 2001). Creative ideas often are disruptive and may lead to significant organizational changes, so

they might invoke resistance from other organizational members who fear that their personal turf will be undermined by the ideas (Yuan \& Woodman, 2010; Zhou \& George, 2001). The energydepleting effect of role ambiguity thus may compromise employees' creative activities, because they lack the drive or stamina to develop new ideas for organizational improvement (Groza et al., 
2016; Quinn et al., 2012). In contrast, when they are not impeded by the uncertainties of unclear job descriptions, employees likely have a greater ability to devote significant energy to the development of productive change-invoking ideas.

Moreover, the frustration that comes with information shortages about their job responsibilities may undermine employees' motivation to come up with new ideas from which their organization could benefit (Amabile, 1996; O'Driscoll \& Beehr, 2000). Employees tend to be less enthusiastic about the possibility of contributing to their organization's success through their positive work activities when they believe that their organization does not care for their well-being (Shalley \& Gilson, 2004; Zhou \& Pan, 2015). Adversity caused by role ambiguity may constitute a signal of the organization's disrespect for employees' daily efforts and contributions (Eathough et al., 2001; Schmidt et al., 2014), such that they come to believe it does not deserve their productive, creative activities. Conversely, to the extent that employees are unencumbered by information shortages about their job responsibilities, the resulting sense of organizational respect may leave them more excited about the possibility of going out of their way to help their organization, through their devoted, creative efforts.

Hypothesis 1: There is a negative relationship between employees' experience of role ambiguity and their creative behavior.

\section{Moderating role of resilience}

We predict a buffering role of resilience in the negative relationship between role ambiguity and creative behavior. As a personal resource, resilience captures the extent to which employees can successfully bounce back and learn from unfavorable situations (Luthans, 2002). To undertake creative behaviors in the presence of significant uncertainties about what their job responsibilities entail, employees must be able to cope with the negative effects that these disruptive behaviors might have for their personal standing in the organization, because other 
members might experience these behaviors as threatening or intrusive (Buchanan \& Badham, 1999; Van Dijk \& Van Dick, 2009). Because the personal resource of resilience fuels employees' energy reservoirs and enhances their ability to find adequate solutions to adverse work situations (Youssef \& Luthans, 2007), the probability that resilient employees experience ambiguous work roles as significant impediments to their creative endeavors should be lower (Hobfoll \& Shirom, 2000). That is, role ambiguity should have a weaker negative relationship with the creative behavior of resilient employees.

Employees equipped with high levels of resilience also might consider information shortages about their job responsibilities as learning opportunities, in terms of how they can pursue disruptive creative behaviors, even in the presence of such workplace adversity (Luthans, 2002). This drive for enhanced learning in turn might motivate employees to leverage some of their energy in creative ways to improve the organization's situation, even in the presence of uncertainties that come with unclear job descriptions (Abbas et al., 2014). As a result, the negative consequences of employees' experience of role ambiguity on their generation of novel ideas should be countered by the anticipated learning outcomes that these creative efforts can generate. Similarly, the anticipation of enhanced learning about how to cope with information shortages in their job responsibilities may reduce their reluctance to undertake creative behaviors, because resilient employees regard the successful undertaking of productive, creative behaviors in the presence of workplace adversity as a positive challenge and a source of personal accomplishment (Luthans, 2002; Youssef \& Luthans, 2007). Thus, the negative relationship between employees' experience of role ambiguity and creative activities should be buffered by their resilience, because employees derive some personal satisfaction from carrying out these activities in the presence of strong role ambiguity. 
Hypothesis 2: The negative relationship between employees' experience of role ambiguity and their creative behavior is moderated by their resilience, such that this relationship is weaker at higher levels of resilience.

\section{Moderating role of task interdependence}

We also hypothesize a buffering role of employees' perceptions of task interdependence — or the extent to which they believe that their job tasks are interconnected with those of their organizational peers (Van der Vegt et al., 2002)—on the negative relationship between role ambiguity and creative behavior. First, the presence of task interdependence tends to increase knowledge sharing among employees (Cabrera \& Cabrera, 2005). Employees whose job performance depends on the input of other members are more likely to reach out to one another to learn how to deal with adverse work conditions, because the interdependencies fuel a need to apply their collective knowledge bases to identify effective solutions (Lin, 2010; Wageman \& Baker, 1997). This increased knowledge sharing in turn should enhance understanding of and appreciation for why their employer may not be able to clarify the job responsibilities of each employee (Kahn et al., 1964; Showail et al., 2013), and accordingly, these employees should possess residual energy that they can devote to productive work behaviors such as creativity (Amabile, 1996; Hobfoll, 2001). That is, the peer knowledge gained through task interdependence should reduce employees' propensity to avoid positive creative behaviors in the presence of resource-draining role ambiguity, because they have a greater ability to understand why their organization might have no choice but to allow some ambiguity in how it defines its employees' job tasks (Hobfoll \& Shirom, 2000).

Second, employees who perceive that their job tasks are closely connected to others' tend to feel a stronger sense of belonging to the organization (Campion, Papper, \& Medsker, 1996; Wageman, 2001), so they might accept uncertainty-inducing organizational practices more 
readily (Eatough et al., 2011). In this sense, employees' perceptions of task interdependence might help counter the decline in their motivation to perform creative activities in the presence of role ambiguity, because they are more forgiving toward their organization (de Jong \& Bal, 2014; Wageman, 2001). Similarly, high levels of task interdependence tend to shift employees' focus of attention, from emphasizing concerns about their personal work situation to making positive contributions to the collective well-being of their organization and its members (Lin, 2010; Wageman \& Baker, 1997). In the presence of high task interdependence, employees accordingly should assign relatively less weight to the challenges that come with resource-draining ambiguities in their work roles and instead feel more motivated to allocate personal energy to generating change-invoking ideas for organizational improvement, even in the presence of role ambiguity (Hobfoll, 2001).

Hypothesis 3: The negative relationship between employees' experience of role ambiguity and their creative behavior is moderated by the perceived interdependence of their job tasks, such that this relationship is weaker at higher levels of task interdependence.

\section{Moderating role of emotion sharing}

Finally, the negative relationship between employees' experience of role ambiguity and their creative behavior should be mitigated if they can openly share their emotions with their peers. Such emotion sharing enables employees to manage and contain the stress that comes with any information deficiencies, because they gain mental support from colleagues who may deal with the same workplace challenge (Stephens et al., 2013). Expressions of personal feelings can instill positive energy in employees by generating a sense of psychological safety (Carmeli \& Gittell, 2009; Quinn et al., 2012), such that it becomes less likely that the energy depletion that they experience due to unclear job descriptions prevents their creative behaviors. In contrast, when they cannot express their personal concerns to organizational peers, employees receive less 
emotional support, in terms of how to cope with an unfavorable work situation such as role ambiguity (Eathough et al., 2001). The energy drainage stemming from information shortages about their job responsibilities then may become more prominent (Schmidt et al., 2014; Singh et al., 2012), with stronger negative effects on employees' ability to develop new ideas for organizational improvement.

In addition, when employees have the opportunity to share their concerns about illdefined job duties with one another, they may gain affirmation from supportive peers that their fears might be unfounded (Nahapiet \& Ghoshal, 1998; Showail et al., 2013), which should help them mitigate negative feelings of frustration or resentment that otherwise would turn them away from positive work activities (Amabile, 1996; Coelho et al., 2011). Similarly, the emotional support that employees enjoy by openly sharing emotions may generate a sense of a shared fate with respect to their exposure to job-related information shortages (Stephens et al., 2013), and these associated feelings of solidarity could reduce the likelihood that their role ambiguity compromises their willingness to undertake creative behaviors. Accordingly, employees should be less likely to respond negatively to role ambiguity, in the form of reduced creative behaviors, to the extent that they can openly express their emotions with organizational colleagues.

Hypothesis 4: The negative relationship between employees' experience of role ambiguity and their creative behavior is moderated by their emotion sharing with organizational peers, such that the relationship is weaker at higher levels of emotion sharing.

\section{Methodology}

To test the research hypotheses, we collected survey data from employees who work for a large Canadian-based organization that operates in the renewable energy sector. Our focus on a single organization avoided the presence of unobserved differences in the external market environment; different organizations may face different external competitive pressures that 
influence the urgency or usefulness of creative behaviors (Dayan \& Di Benedetto, 2011). Moreover, the renewal energy sector is marked by significant developments and innovations (Zolfaghari \& Rialp Criado, 2018), so our focus on understanding employees' propensity to generate change-invoking ideas that could contribute to their organization's success is highly relevant in this study context.

After the organization's top management endorsed the study, we asked 300 randomly selected employees to participate. A cover letter accompanying the survey emphasized that participants would enjoy complete confidentiality, that there were no good or bad answers, that it was normal for different respondents to give varied responses to the questions, and that it was important they answered the questions as honestly as possible. These clarifications helped minimize social desirability or acquiescence biases (Spector, 2006). We received 99 completed responses, for a response rate of 33\%. Among the respondents, $20 \%$ were women, they were 41 years old on average, and they had worked for the organization for 7 years. A correlation analysis revealed no significant relationships between these three individual characteristics and employees' creative behavior. Based on Becker's (2005) recommendation for the treatment of irrelevant control variables, we did not include them as controls in the regression models.

\section{Measures}

The measurement scales for the five focal constructs came from previous research and used seven-point Likert scales, ranging from 1 ("strongly disagree") to 7 ("strongly agree").

Creative behavior. Employee creative behavior was captured with a three-item scale drawn from previous research (De Clercq et al., 2017; Janssen, 2001). For example, employees indicated whether "I often generate original solutions to problems" and "I often create new ideas for improvement" (Cronbach's alpha $=.92)$. Some studies use supervisor ratings to assess 
employee creativity (e.g., George \& Zhou, 2001; Oldham \& Cummings, 1996), but self-reported creativity measures are not uncommon (e.g., Kaufman \& Baer, 2004; Shalley, Gilson, \& Blum, 2009) and may even be preferable (Zhou, Shin, \& Cannella, 2008). Supervisors often lack the ability to observe the entire range of creative activities that employees undertake, so selfperceived measures may provide more insights (Hocevar, 1981; Zhou et al., 2008). In addition, creative behaviors are goal directed and intentional (Shalley, 1991), so their assessment by the employees themselves, who are most aware of and knowledgeable about their actual involvement (Janssen, 2000; Lumsden, 1999), has great value. When self-reports are appropriate, concerns about common method bias are mitigated too (Conway \& Lance, 2010). Moreover, previous studies confirm positive and significant correlations between self-rated creativity and established creativity measures, such as the Barron Welsh Art Scale (Furnham, 1999) and the Torrance Tests of Creative Thinking (Reiter-Palmon, Robinson-Morral, Kaufman, \& Santo, 2012; cf. Sarac, Efil, \& Eryilmaz, 2014). Finally, creative behaviors originate from conscious choices by individual employees (Ford, 1996), so they cannot be viewed in isolation of employees' own subjective experiences (Csikszentmihalyi, 1990). Therefore, investigating why some employees are more likely than others to undertake creative activities, based on their own self-perceptions, has significant value for understanding the creativity process (Zhou et al., 2008)

Role ambiguity. We measured employees' experience of ambiguous work roles with a six-item reverse-coded scale of role clarity, drawn from Fried and Tiegs (1995). Employees assessed, for example, whether "I know exactly what is expected of me" and "I know what my responsibilities are" (Cronbach's alpha $=.94)$.

Resilience. We measured employees' resilience levels with a five-item scale based on Stephens and colleagues (2013). Two example items were "I bounce back when I confront 
setbacks at work" and "Dealing with difficult colleagues or situations enables me to grow" $($ Cronbach's alpha $=.83)$.

Task interdependence. We assessed the extent to which employees believed that the successful completion of their job tasks depended on the input of other organizational members, with a three-item scale based on previous research (De Clercq, Dimov, \& Thongpapanl, 2015; Fisher, Maltz, \& Jaworski, 1997). For example, employees rated whether "My own performance depends on receiving information and advice from my colleagues" and "I depend on my colleagues' work for help and support that I need to do my job" (Cronbach's alpha $=.94$ ).

Emotion sharing. To capture employees' willingness to express their emotions openly with peers, we relied on a three-item scale of emotional carrying capacity (Stephens et al., 2013). Two example items were "I can fully express my emotions to my colleagues" and "When my colleagues and I interact with each other, we express both positive and negative feelings to each other" (Cronbach's alpha $=.92)$.

The validity of the study's constructs was assessed with a five-factor model, using confirmatory factor analysis (Anderson \& Gerbing, 1988). This model indicated adequate fit: $\chi^{2}(199)=379.85$, incremental fit index $=.91$, Tucker-Lewis index $=.88$, and confirmatory fit index $=.91$. The factor loadings of all items on their respective constructs were strongly significant $(p<.001)$, suggesting the presence of convergent validity (Gerbing \& Anderson, 1988). Evidence of discriminant validity came from the comparison of the fit of constrained models, in which the correlation between two constructs was set to equal 1, with that of their unconstrained counterparts, in which the correlations between the constructs were free to vary. For each of the ten pairs that could be generated from the five constructs, the unconstrained 
models achieved superior fit $\left(\Delta \chi^{2}(1)>.3 .84, p<.05\right)$, in support of the presence of discriminant validity (Anderson \& Gerbing, 1988).

We performed two statistical tests to address possible concerns related to the use of common respondents. First, with Harman's one-factor test (Podsakoff \& Organ, 1986), we assessed whether a single factor model that included all five constructs - creative behavior, role ambiguity, resilience, task interdependence, and emotion sharing - might account for a majority of the total variance in the data. The first extracted factor explained only $46 \%$ of the variance, so common method bias does not seem to be a significant concern. Second, we undertook a confirmatory factor analysis to compare the fit of the five-factor model with that of a one-factor model in which each item loaded on a single factor. The former model revealed superior fit $\left(\Delta \chi^{2}(10)=905.06, p<.001\right)$, which further diminishes the possibility of common method bias (Lattin, Carroll, \& Green, 2003). Finally, common method bias tends to be less of a concern in theoretical models that include moderating effects, because it is more difficult for respondents to anticipate these effects and tailor their responses accordingly (Brockner, Siegel, Daly, Tyler, \& Martin, 1997; Simons and Peterson 2000).

\section{Results}

Table 1 contains the zero-order correlations and descriptive statistics, and Table 2 reports the regression results. Model 1 included role ambiguity; Model 2 added the three moderators of resilience, task interdependence, and emotion sharing; and Models 3-5 added the role ambiguity $\times$ resilience, role ambiguity $\times$ task interdependence, and role ambiguity $\times$ emotion sharing interaction terms, respectively. Previous studies indicate that it is appropriate to add multiple interaction terms in separate equations, because their simultaneous assessment in one and the same model might mask their true moderating effects (Aiken \& West, 1991; Covin, Green, \& 
Slevin, 2006; De Clercq, Bouckenooghe, Raja, \& Matsyborska, 2014). For each of the two-way interaction terms, we adopted the well-established approach of mean-centering the product terms (Aiken \& West, 1991).

[Insert Tables 1 and 2 about here]

In support of our baseline prediction that information deficiencies about job descriptions might steer employees away from productive work behaviors, Model 1 revealed a strong negative relationship between role ambiguity and creative behavior $(\beta=-.401, p<.001)$, in line with Hypothesis 1. Although these relationships were outside the theoretical scope of this study, the results in Model 2 also indicated direct positive relationships of resilience $(\beta=.357, p<.01)$, and emotion sharing $(\beta=.235, p<.05)$ with creativity behavior, but there was no such significant relationship for task interdependence $(\beta=.105, n s)$.

Models 3-5 provided support for the hypothesized buffering effects of resilience $(\beta=$ $.151, p<.01)$, task interdependence $(\beta=.088, p<.05)$, and emotion sharing $(\beta=.082, p<.05)$ on the negative relationship between role ambiguity and creative behavior. The likelihood that increasing levels of role ambiguity inhibit creative behavior diminished to the extent that employees were resilient to difficult work situations (Hypothesis 2), perceived high levels of task interdependence (Hypothesis 3), and could openly express their emotions (Hypothesis 4). We depict these buffering effects in Figures 2-4, affirming that the likelihood that role ambiguity would escalate into reduced creative behaviors was lower at higher levels of the three moderators, in further support of our conceptual framework.

[Insert Figures 2-4 about here]

\section{Discussion}


This research extends previous studies by investigating how employees' access to relevant resources can serve as buffers against the likelihood that unclear job descriptions lead to less creative behaviors. The paucity of attention to this important issue is somewhat surprising, because the uncertainty that results from inadequate information provision about work roles arguably can be reduced by access to energy-enhancing resources (Ralston et al., 2010; Schmidt et al., 2014). Drawing from COR theory (Hobfoll, 1989, 2001), we have investigated in particular how three selected resources—resilience, task interdependence, and emotion sharingmight reduce employees' negative reactions to ambiguous work roles, in the form of a reluctance to undertake creative activities. The empirical findings support our theoretical claims.

Specifically, the direct negative relationship between role ambiguity and creative behavior is consistent with previous studies of the harmful effects of role stress in terms of discouraging other positive work activities, such as organizational citizenship behavior (Chen et al., 2013) or prosocial service behavior (Malhotra \& Ackfeldt, 2016). Ambiguous work roles might inhibit creative behaviors because of the resource drainage that employees suffer, due to their organization's failure to provide them with clear information about their job duties (Cordes \& Dougherty, 1993; Singh et al., 2012). In such a scenario, employees may feel compelled to focus on "easy" job activities first, rather than change-invoking activities that might be met with resistance, so they refrain from investing significant energy in generating novel ideas that could disrupt the organizational status quo (Coelho et al., 2011; Hobfoll, 2001). Moreover, the negative relationship between role ambiguity and creative behavior is informed by employees' frustration with job-related information deficiencies, which leaves them less motivated to devote significant time to positive work activities from which their organization otherwise would benefit (Amabile, 1996; O'Driscoll \& Beehr, 2000). Negative feelings of disappointment or frustration, in response 
to ambiguous work roles, appear to diminish employees' willingness to dedicate substantial efforts to carrying out energy-consuming creative activities.

As its central contribution however, this study elaborates how three energy-enhancing resources - resilience, task interdependence, and emotion sharing - mitigate the negative relationship between employees' experience of role ambiguity and their creative behaviors. First, employees' resilience prevents role ambiguity from reducing the likelihood of novel idea generation, because resilient employees can deal better with and recover from any resistance or setbacks that might arise in response to their disruptive behaviors (Luthans, 2002). That is, the likelihood that the experience of role ambiguity translates into reduced creative efforts is lower to the extent that employees can draw from greater energy reservoirs, fuelled by their own resilience (Quinn et al., 2012; Youssef \& Luthans, 2007). Moreover, when their resilience is high, employees' intrinsic motivation to undertake discretionary creative efforts might offset the frustration that tends to arise in response to information shortages in role descriptions (Ryan \& Deci, 2000; Youssef \& Luthans, 2007). In this sense, the escalation of negativity, due to role ambiguity, into a reduced willingness to contribute creative behaviors to the organization can be avoided.

Second, employees' perception of task interdependence functions as a buffer against the resource-depleting effect of ambiguous work roles. Enhanced knowledge sharing, prompted by employees' interrelated job tasks (Cabrera \& Cabrera, 2005), can generate a better understanding of the different ways employees might undertake productive, creative activities, even in the presence of job-related information shortages, so their reluctance to pursue such activities should diminish (Showail et al., 2012). High levels of task interdependence also might stimulate a sense of organizational belonging (Lin, 2010; Wageman, 2001), such that employees are more likely to 
tolerate the uncertainties that come with information deficiencies (Schmidt et al., 2014;

Trépanier et al., 2013). In this case, it becomes less likely that they use their work hardships as excuses to avoid productive creative behaviors.

Third, the mitigating role of emotion sharing reveals that the inclination to refrain from creative behaviors in response to the frustration of unclear work roles is lower when employees feel comfortable expressing their emotions, both positive and negative, to their organizational colleagues (Stephens et al., 2013). When employees can count on this sort of support from other organizational members, who might also suffer from ill-defined role descriptions, it becomes less likely that they will feel unable to carry out energy-consuming work behaviors (Hobfoll \& Shirom, 2000). Sharing personal frustrations that arise due to excessive role ambiguity, and the corresponding feeling of solidarity, also may have a motivational element, such that it becomes less likely that employees' distress about incomplete job descriptions escalates into a refusal to assist their organization with creative activities (Stephens et al., 2013). In contrast, at low levels of emotion sharing, employees receive less peer support that might help them cope with information shortages, and they cannot easily express their preoccupations. A reluctance to engage in creative behaviors then becomes a more likely response to this adverse work situation.

Our conceptual focus on the buffering roles of the three resources reflects the incremental influence of role ambiguity on reduced creative behaviors. We thus provide organizations with deeper insights into the circumstances in which resource depletion caused by role ambiguity is less likely to keep their employees from developing change-invoking ideas that could enhance organizational success. Empirically, this issue comes to the fore in the slope patterns in Figures 2-4. That is, higher levels of role ambiguity inhibit creative behaviors to a lesser extent among employees who easily bounce back from setbacks at work, believe that they are operating in 
interdependent task environments, and can freely express their personal feelings with peers. This study thus offers an expanded understanding of when role ambiguity is likely to inhibit creativity, by specifying the combined influences of role ambiguity and the three critical energyenhancing resources of resilience, task interdependence, and emotion sharing.

\section{Limitations and future research}

Some limitations of this study suggest avenues for further research. First, the data collection took place at one point in time, creating possible concerns about reverse causality. That is, employees' creative behaviors might help them find ways to do their jobs more effectively and thereby reduce perceptions of role ambiguity (Amabile, 1996; Gong et al., 2009). Our hypotheses are based in the well-established COR theory-according to which there is a negative causal connection between a resource-depleting work condition such as role ambiguity and the likelihood of carrying out energy-consuming productive work activities (Hobfoll, 1989) — but future research could adopt longitudinal designs to investigate the causal processes that underlie the relationship between role ambiguity and creative behavior explicitly, as well as the contingent factors that inform this process. In a related vein, we theorized that both ability and motivation mechanisms underpin the relationship between role ambiguity and reduced creativity, together with the buffering roles of three resources. Additional studies could measure these mechanisms directly to assess which might be most prominent.

Second, in choosing the three focal contingencies, we explicitly sought representations of positive energy creation at three distinct levels - individual (resilience), job task (task interdependence), and relational (emotion sharing) — to achieve a comprehensive set of relevant factors. Further research could consider additional potential buffers of the negative relationship between role ambiguity and creativity too. For example, the likelihood that information 
deficiencies stop employees from developing change-invoking ideas for organizational improvement might be mitigated by individual factors such as employees' creative self-efficacy (Tierney \& Farmer, 2002) or passion for work (Baum \& Locke, 2004), as well as by contextual factors such as employees' perceptions of organizational justice (Colquitt, Conlon, Wesson, Porter, \& Ng, 2001), trust in top management (Holland, Cooper, Pyman, \& Teicher, 2012), or person-work context fit (Chen, Chang, \& Chang, 2015).

Third, an empirical weakness of this research is its relatively small sample size, generated from employees in one organization. These conditions might limit the generalizability of the findings, but smaller sample sizes arguably provide more conservative statistical tests of theoretical relationships, particularly for conceptual frameworks that include multiple moderating effects (Bouckenooghe, De Clercq, \& Deprez, 2014). Moreover, our theoretical arguments are not industry-specific, but continued research could include multiple organizations from different industries to investigate, for example, how relevant industry factors such as the level of external competitive rivalry might leave employees more willing to contribute to their organization's success through creative behaviors, even in the presence of adverse work conditions (Lahiri, Pérez-Nordtvedt, \& Renn, 2008; Porter, 1996).

\section{Practical implications}

This study of the concurrent influences of employees' experience of role ambiguity and resource access on their creative behaviors also has implications for managerial practice. When employees suffer from information shortages and are unclear about their job responsibilities, their energy reservoirs might become so depleted that they stay away from productive work activities. Yet many employees may be reluctant to admit that they suffer from such information deficiencies, because they do not want to appear uninformed or ask questions that might imply 
they do not know what they are doing (Kahn et al., 1964; Schmidt et al., 2014). Accordingly, organizations should be proactive in reducing the sources of ambiguity for their employee bases, such as by formalizing role descriptions through written documentation (Dyer \& Song, 1998) or adopting feedback mechanisms that encourage employees to request transparency about what is expected of them (Pearson, 1991). Organizations also could clarify both the ends (e.g., specific performance targets) and means (e.g., budget, time) of employees' job obligations, particularly among newly recruited employees. For example, organizations could implement integration programs that clarify newcomers' job responsibilities through dedicated job training or by connecting newcomers with experienced organizational peers who hold similar job positions.

The study's findings have perhaps the most practical value though for organizations that are not able to avoid some information shortages, due to the complexity of their internal operations or their need for flexibility (Elovainio \& Kivimäki, 2001; Schmidt et al., 2014). These organizations can benefit from hiring and retaining resilient employees who effectively bounce back from setbacks and are motivated to learn from them. To boost employees' resilience, organizations could teach them how to anticipate and prepare for various adverse work situations, then identify different pathways to minimize the chances that these situations compromise the effectiveness of their daily functioning (Masten, 2001). Organizations can also benefit from making employees aware of the interrelatedness of their job tasks and stimulating knowledge sharing routines to support collective job tasks. Such knowledge exchanges can provide employees with critical insights into how to cope with ambiguous work roles (Showail et al., 2012), leaving room for them to carry out additional, energy-consuming, creative activities. Finally, organizations might work to contain the negative consequences of the presence of ambiguous work roles by promoting a culture in which employees feel comfortable expressing 
their concerns (Stephens et al., 2013). Employees who can count on the emotional support of organizational peers are better positioned to cope with the stress that comes with job-related information shortages, which should lower their inclination to avoid productive work behaviors such as creativity. In contrast, when employees feel a weak emotional connection with colleagues, they may be less prone to reach out to find a sounding board who also will give them advice about how to deal with incomplete job descriptions, while still finding time for creative pursuits. In turn, the training and assessment of employees could be based, at least in part, on whether they are open to listening to others' concerns and finding novel ways to contribute collectively to their organization's success, even in the presence of adverse work conditions.

\section{Conclusion}

With a basis in COR theory, this study reveals when employees' suffering from ambiguous work roles is less likely to diminish their creative behavior. The likelihood that information shortages about job responsibilities inhibit the generation of change-invoking ideas that otherwise could contribute to organizational effectiveness diminishes to the extent that employees are resilient, have interdependent job tasks, and openly share their emotions with colleagues. These resources inform employees' ability and motivation to cope effectively with a lack of adequate information about their job obligations, such that their allocation of effort to productive creative behaviors is compromised to a lesser extent. We hope in turn that this study functions as a catalyst for further examinations of how organizations can reduce the risk that ambiguous work roles escalate into negative responses, in the form of curtailed positive work behaviors such as creativity. 


\section{References}

Abbas, M., Raja, U., Darr, W., \& Bouckenooghe, D. (2014). Combined effects of perceived politics and psychological capital on job satisfaction, turnover intentions, and performance. Journal of Management, 40, 1813-1830.

Aiken, L.S., \& West, S.G. (1991). Multiple regression: Testing and interpreting interactions. Newbury Park, CA: Sage.

Aleksic, D., \& Mihelic, K.K., Cerne, M., \& Skerlavaj, M. (2017). Interactive effects of perceived time pressure, satisfaction with work-family balance (SWFB), and leader-member exchange (LMX) on creativity. Personnel Review, 46, 662-679.

Amabile, T.M. (1996). Creativity in context. Boulder, CO: Westview.

Anderson, J.C., \& Gerbing, D.W. (1988). Structural equation modeling in practice: A review and recommended two-step approach. Psychology Bulletin 1033, 411-423.

Argyris, C., \& Schon, D. (1978). Organizational learning: A theory of action approach, reading. Boston, MA: Addison Wesley.

Baum, J.R., \& Locke, E.A. (2004). The relationship of entrepreneurial traits, skill, and motivation to subsequent venture growth. Journal of Applied Psychology, 89, 587-598.

Becker, T.E. (2005). Potential problems in the statistical control of variables in organizational research: A qualitative analysis with recommendations. Organizational Research Methods, 8, $274-289$.

Bogilovic, S., Cerne, M.\& Skerlavaj, M. (2017). Hiding behind a mask? Cultural intelligence, knowledge hiding, and individual and team creativity. European Journal of Work and Organizational Psychology, 26, 710-723.

Bouckenooghe, D., De Clercq, D., \& Deprez, J. (2014). Interpersonal justice, relational conflict, and commitment to change: The moderating role of social interaction. Applied Psychology: An International Review, 63, 509-540.

Brockner, J., Siegel, P. A., Daly, J. P., Tyler, T., \& Martin, C. (1997). When trust matters: The moderating effect of outcome favourability. Administrative Science Quarterly, 42, 558-583.

Buchanan, D., \& Badham, R. (1999). Politics and organizational change: The lived experience. Human Relations, 52(5), 609-629.

Cabrera, E. F. and Cabrera, A. (2005). Fostering knowledge sharing through people management practices. International Journal of Human Resource Management 16: 720-735.

Campion, M. A., Papper, E. A., \& Medsker, G. J. (1996). Relations between team characteristics and effectiveness: a replication and extension. Personnel Psychology, 49, 429-452.

Carmeli, A., \& Gittell, J. H. (2009). High-quality relationships, psychological safety, and learning from failures in work organizations. Journal of Organizational Behavior, 709-729.

Chen, M.-F., Lin, C.-P., \& Lien, G.-Y. (2011). Modelling job stress as a mediating role in predicting turnover intention. Service Industries Journal, 31, 1327-1345.

Chen, M. H., Chang, Y. Y., \& Chang, Y. C. (2015). Exploring individual-work context fit in affecting employee creativity in technology-based companies. Technological Forecasting and Social Change, 98, 1-12.

Chen, M.-H., \& Kaufmann, G. (2008). Employee creativity and R\&D: A critical review. Creativity and Innovation Management, 17(1), 71-76.

Chen, Z., Takeuchi, R., \& Shum, C. (2013). A social information processing perspective of coworker influence on a focal employee. Organization Science, 24, 1618-1639. 
Coelho, F., Augusto, M., \& Lages, L.F. (2011). Contextual factors and the creativity of frontline employees: The mediating effects of role stress and intrinsic motivation. Journal of Retailing, 87, 31-45.

Colquitt, J.A., Conlon, D.E., Wesson, M.J., Porter, C.O.L.H., \& Ng, K.Y. (2001). Justice at the millennium: A meta-analytic review of 25 years of organizational justice research. Journal of Applied Psychology, 86, 425-445.

Conway, J.M., \& Lance, C.E. (2010). What reviewers should expect from authors regarding common method bias in organizational research. Journal of Business Psychology, 25: 325334.

Cordes, C.L., \& Dougherty, T.W. (1993). A review and an integration of research on job burnout. Academy of Management Review, 18, 621-656.

Covin, J.G., Green, K.M., \& Slevin, D.P. (2006). Strategic process effects on the entrepreneurial orientation-sales growth rate relationship. Entrepreneurship Theory \& Practice, 30, 57-81.

Csikszentmihalyi, M. (1990). Flow. New York: HarperCollins.

Dayan, M., \& Di Benedetto, C. (2011). Team intuition as a continuum construct and new product creativity: The role of environmental turbulence, team experience, and stress. Research Policy, 40, 276-286.

De Clercq, D., Bouckenooghe, D., Raja, U., \& Matsyborska, G. (2014). Unpacking the goal congruence-organizational deviance relationship: The roles of work engagement and emotional intelligence. Journal of Business Ethics, 124, 695-711.

De Clercq, D., Dimov, D., \& Thongpapanl, N (2015). Structural and relational interdependence and entrepreneurial orientation in SMEs: The mediating role of internal knowledge sharing. International Small Business Journal, 33, 514-536.

De Clercq, D., Rahman, Z.M., \& Belausteguigoitia, I. (2017). Task conflict and employee creativity: The critical roles of learning orientation and goal congruence. Human Resource Management, 56, 93-109.

de Jong, S.B., \& Bal, P.M. (2014). How asymmetrical task dependence and task interdependence interact: An individual level study into the effects on affective reactions. Journal of Managerial Psychology, 29, 1115-1132,

Dyer, B., \& Song, X.M. (1998). Innovation strategy and sanctioned conflict: A new edge in innovation? Journal of Product Innovation Management, 15, 505-519.

Eatough, E.M., Chang, C.H., Miloslavic, S.A., \& Johnson, R.E. (2011). Relationships of role stressors with organizational citizenship behavior: A meta-analysis. Journal of Applied Psychology, 96, 619-632.

Elovainio, M., \& Kivimäki, M. (2001). The effects of personal need for structure and occupational identity in the role stress process. Journal of Social Psychology, 141, 365-378.

Fisher, R.J., Maltz, E., and Jaworski, B.J. (1997). Enhancing communication between marketing and engineering: The moderating role of relative functional identification. Journal of Marketing, 61(3), 54-70.

Ford, C. M. (1996). A theory of individual creative action in multiple social domains. Academy of Management Review, 21, 1112-1142.

Fried, Y., \& Tiegs, R. (1995). Supervisors' role conflict and role ambiguity differential relations with performance ratings of subordinates and the moderating effect of screening ability. Journal of Applied Psychology, 80, 282-291.

Furnham, A. (1999). Personality and creativity. Perceptual and Motor Skills, 88, 407-408. 
George, J. M., \& Zhou, J. (2001). When openness to experience and conscientiousness are related to creative behavior: An interactional approach. Journal of Applied Psychology, 86, 513-524.

Gerbing D.W., \& Anderson, J.C. (1988). An updated paradigm for scale development incorporating unidimensionality and its assessment. Journal of Marketing Research 25, 186-192.

Gong, Y., Huang, J.-C., \& Farh, J.-L. (2009). Employee learning orientation, transformational leadership, and employee creativity: The mediating role of employee creative self-efficacy. Academy of Management Journal, 52(4), 765-778.

Groza, M.D., Locander, D.A., \& Howlett, C.H. (2016). Linking thinking styles to sales performance: The importance of creativity and subjective knowledge. Journal of Business Research, 69, 4185-4193..

Hobfoll, S.E. (1989). Conservation of resources: A new attempt at conceptualizing stress. American Psychologist, 44: 513-524.

Hobfoll, S.E. (2001). The influence of culture, community, and the nested-self in the stress process: Advancing conservation of resource theory. Applied Psychology: An International Review, 50, 337-369.

Hobfoll, S.E., \& Shirom, A. (2000). Conservation of resources theory: Applications to stress and management in the workplace. In R.T. Golembiewski (Ed.), Handbook of organization behavior (2d ed., pp. 57-81). Dekker, New York.

Hocevar, D. (1981). Measurement of creativity: Review and critique. Journal of Personality Assessment, 45, 450-464.

Holland, P., Cooper, B.K. Pyman, A., \& Teicher, J. (2012). Trust in management: the role of employee voice arrangements and perceived managerial opposition to unions. Human Resource Management Journal, 22, 377-391.

Janssen, O. (2000). Job demands, perceptions of effort-reward fairness, and innovative work behavior. Journal of Occupational and Organizational Psychology, 73, 287-302.

Janssen, O. (2001). Fairness perceptions as a moderator in the curvilinear relationships between job demands, and job performance and job satisfaction. Academy of Management Journal, 44, 1039-1050.

Kahn, R., Wolfe, D., Quinn, R., Snoek, J., \& Rosenthal, R. (1964). Organizational stress: Studies in role conflict and ambiguity. New York: Wiley.

Kark, R., Van Dijk, D., \& Vashdi, D.R. (2018). Motivated or demotivated to be creative: The role of self-regulatory focus in transformational and transactional leadership processes. Applied Psychology: An International Review, 67, 186-224.

Kaufman, J.C., \& Baer, J. (2004). Sure, I'm creative - but not in math! Self-reported creativity in diverse domains. Empirical Studies of the Arts, 22, 143-155.

Kim, T.-Y., Hon, A.H., \& Crant, J.M. (2009). Proactive personality, employee creativity, and newcomer outcomes: A longitudinal study. Journal of Business and Psychology, 24, 93-103.

Kotter, J. P., \& Schlesinger, L. A. (1979). Choosing strategies for change. Harvard Business Review, 57, 106-114.

Lahiri, S., Pérez-Nordtvedt, L., \& Renn, R.W. (2008). Will the new competitive landscape cause your firm's decline? It depends on your mindset. Business Horizons, 51, 311-320.

Lattin, J.M., Carroll, J.D., \& Green, P.E. (2003). Analyzing multivariate data. Belmont, CA: Thomson Brooks/Cole. 
Lin, C.-P. (2010). Learning task effectiveness and social interdependence through the mediating mechanisms of sharing and helping: A survey of online knowledge workers. Group \& Organization Management 35(3): 299-328.

Lumsden, C.J. (1999). Evolving creative minds: Stories and mechanisms. In R. J. Sternberg (Ed.), Handbook of creativity (pp. 153-168). New York: Cambridge University Press.

Luthans, F. (2002). The need for and meaning of positive organizational behavior. Journal of Organizational Behavior, 23, 695-706.

Maimone, F., \& Sinclair, M. (2014). Dancing in the dark: Creativity, knowledge creation and (emergent) organizational change. Journal of Organizational Change Management, 27(2), 344-361.

Malhotra, N., \& Ackfeldt, A.-L. (2016). Internal communication and prosocial service behaviors of front-line employees: Investigating mediating mechanisms. Journal of Business Research, 69, 4132-4139.

Masten, A.S. (2001). Ordinary magic: Resilience process in development. American Psychologist, 56, 227-239.

Nahapiet, J. \& Ghoshal, S. (1998). Social capital, intellectual capital, and the organizational advantage. Academy of Management Review, 23, 242-268.

O’Driscoll, M., \& Beehr, T. (2000). Moderating effects of perceived control and need for clarity on the relationship between role stressors and employee affective reactions. Journal of Social Psychology, 140, 15 1-159.

Oldham, G. R., \& Cummings, A. (1996). Employee creativity: Personal and contextual factors at work. Academy of Management Journal, 39, 607-634.

Parboteeah, K. P., Hoegl, M., \& Muethel, M. (2015). Team characteristics and employees' individual learning: A cross-level investigation. European Management Journal, 33(4), 287 295.

Pearson, CA.L. (1991). An assessment of extrinsic feedback on participation, role perceptions, motivation, and job satisfaction in a self-managed system for monitoring group achievement. Human Relations, 44, 517-537.

Podsakoff, P.M., \& D.W. Organ (1986). Self-reports in organization research: Problems and prospects, Journal of Management, 12, 532-544.

Porter, M.E. (1996). What is strategy? Harvard Business Review, 74, 61-81.

Quinn, R.W., Spreitzer, G.M., \& Lam, C.F. (2012). Building a sustainable model of human energy in organizations: Exploring the critical role of resources. Academy of Management Annals, 6, 337-396.

Ralston, D.A., Lee, C.H., Perrewé, P.L., Van Deusen, C., Vollmer, G.R., et al. (2010). A multisociety examination of the impact of psychological resources on stressor-strain relationships. Journal of International Business Studies, 41, 652-670.

Reiter-Palmon, R., Robinson-Morral, E. J., Kaufman, J. C., \& Santo, J. B. (2012). Evaluation of self-perceptions of creativity: Is it a useful criterion? Creativity Research Journal, 24, 107114.

Ryan, R.M., \& Deci, E.L. (2000). Self-determination theory and the facilitation of intrinsic motivation, social development, and well-being. American Psychologist, 55(1): 68-78.

Sarac, M., Efil, I., \& Eryilmaz, M. (2014). A study of the relationship between personorganization fit and employee creativity. Management Research Review, 37, 479-450. 
Schmidt, S., Roesler, U., Kusserow, T., \& Rau, R. (2014). Uncertainty in the workplace: Examining role ambiguity and role conflict, and their link to depression-a meta-analysis. European Journal of Work and Organizational Psychology, 23, 91-106.

Seibert, S. E., Kraimer, M. L., \& Crant, J. M. (2001). A longitudinal model linking proactive personality and career success. Personnel Psychology, 54, 845-874.

Shalley, C. E. (1991). Effects of productivity goals, creativity goals, and personal discretion on individual creativity. Journal of Applied Psychology, 76, 179-185.

Shalley, C.E., \& Gilson, L.L. (2004). What leaders need to know: A review of social and contextual factors that can foster or hinder creativity. The Leadership Quarterly, 15, 33-53.

Shalley, C. E., Gilson, L. L., \& Blum, T. C. (2009). Interactive effects of growth need strength, work context, and job complexity on self-reported creative performance. Academy of Management Journal, 52, 489-505.

Showail, S.J., McClean Parks, J., \& Smith, F.L. (2013). Foreign workers in Saudi Arabia: a field study of role ambiguity, identification, information-seeking, organizational support and performance. International Journal of Human Resource Management, 24, 3957-3979.

Si, S., \& Wei, F. (2012). Transformational and transactional leaderships, empowerment climate, and innovation performance: A multilevel analysis in the Chinese context. European Journal of Work and Organizational Psychology, 21(2), 299-320.

Simons, T., \& Peterson, R.S. (2000). Task conflict and relationship conflict in top management teams: The pivotal role of intragroup trust. Journal of Applied Psychology, 83, 102-111.

Singh, P., Suar, D., \& Leiter, M.P. (2012). Antecedents, work-related consequences, and buffers of job burnout among Indian software developers. Journal of Leadership \& Organizational Studies, 19, 83-104.

Spector, P.E. (2006). Method variance in organizational research: Truth or urban legend? Organizational Research Methods, 9, 221-232.

Stephens, J. P., Heaphy, E. D., Carmeli, A., Spreitzer, G. M., \& Dutton, J. E. (2013). Relationship quality and virtuousness: Emotional carrying capacity as a source of individual and team resilience. Journal of Applied Behavioral Science, 49, 13-41.

Sutton, R. I., \& Hargadon, A. (1996). Brainstorming groups in context: Effectiveness in a product design firm. Administrative Science Quarterly, 685-718.

Tierney, P., \& Farmer, S.M. (2002). Creative self-efficacy: Potential antecedents and relationship to creative performance. Academy of Management Journal, 45, 1137-1148.

Tierney, P., Farmer, S. M., \& Graen, G. B. (1999). An examination of leadership and employee creativity: The relevance of traits and relationships. Personnel Psychology, 52(3), 591-620.

Trépanier, S.-G., Fernet, C., \& Austin, S. (2013). The moderating role of autonomous motivation in the job demands-strain relation: A two sample study. Motivation and Emotion, 37, 93-105.

Van der Vegt, G., Emans, B., and Van de Vliert, E. (2002). Team members' affective responses to patterns of intragroup interdependence and job complexity. Journal of Management, 26, 633-655.

Van Dijk, R., \& Van Dick, R. (2009). Navigating organizational change: Change leaders, employee resistance and work-based identities. Journal of Change Management, 9, 143-163.

Wageman, R. (2001). The meaning of interdependence. In Groups at work: Theory and research, M.E. Turner (Ed.). Mahwah, NJ: Erlbaum, 197-218.

Wageman, R. and G.P. Baker (1997). Incentives and cooperation: the joint effects of task and reward interdependence on group performance. Journal of Organizational Behavior 18: 139158. 
Youssef, C.M., \& Luthans, F. (2007). Positive organizational behavior in the workplace. Journal of Management, 33, 774-800.

Yuan, F., \& Woodman, R. W. (2010). Innovative behavior in the workplace: The role of performance and image outcome expectations. Academy of Management Journal, 53, 323342.

Zhang, R.-P., Tsingan, L., \& Zhang, L.-P. (2013). Role stressors and job attitudes: A mediated model of leader-member exchange. Journal of Social Psychology, 153, 560-576.

Zhou, J., \& George, J. M. (2001). When job dissatisfaction leads to creativity: Encouraging the expression of voice. Academy of Management Journal, 44, 682-696.

Zhou, J., Shin, S. J., \& Canella, A. A., Jr. (2008). Employee self-perceived creativity after mergers and acquisitions: Interactive effects of threat-opportunity perception, access to resources, and support for creativity. Journal of Applied Behavioral Science, 44, 397-421.

Zhou, Q., Martinez, L.F., Ferreira, A.I., \& Rodrigues, P. (2016). Supervisor support, role ambiguity and productivity associated with presenteeism: A longitudinal study. Journal of Business Research, 69, 3380-3387.

Zhou, Q., \& Pan, W. (2015). A cross-level examination of the process linking transformational leadership and creativity: The role of psychological safety climate. Human Performance, 28, 405-424.

Zolfaghari, M., \& Rialp Criado, A. (2018). International ecopreneurs: The case of ecoentrepreneurial new ventures in the renewable energy industry. Journal of International Entrepreneurship, 1-24. 
Figure 1. Conceptual Model

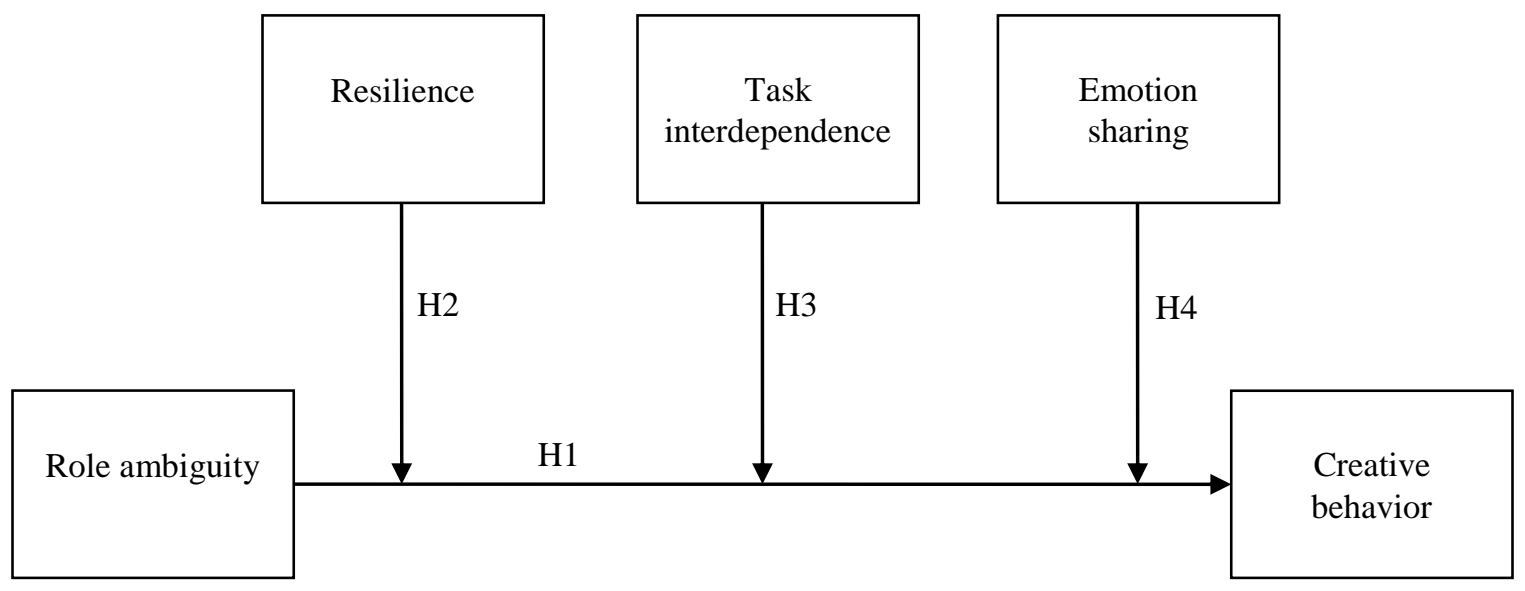


Figure 2. Moderating effect of resilience on the relationship between role ambiguity and creative behavior

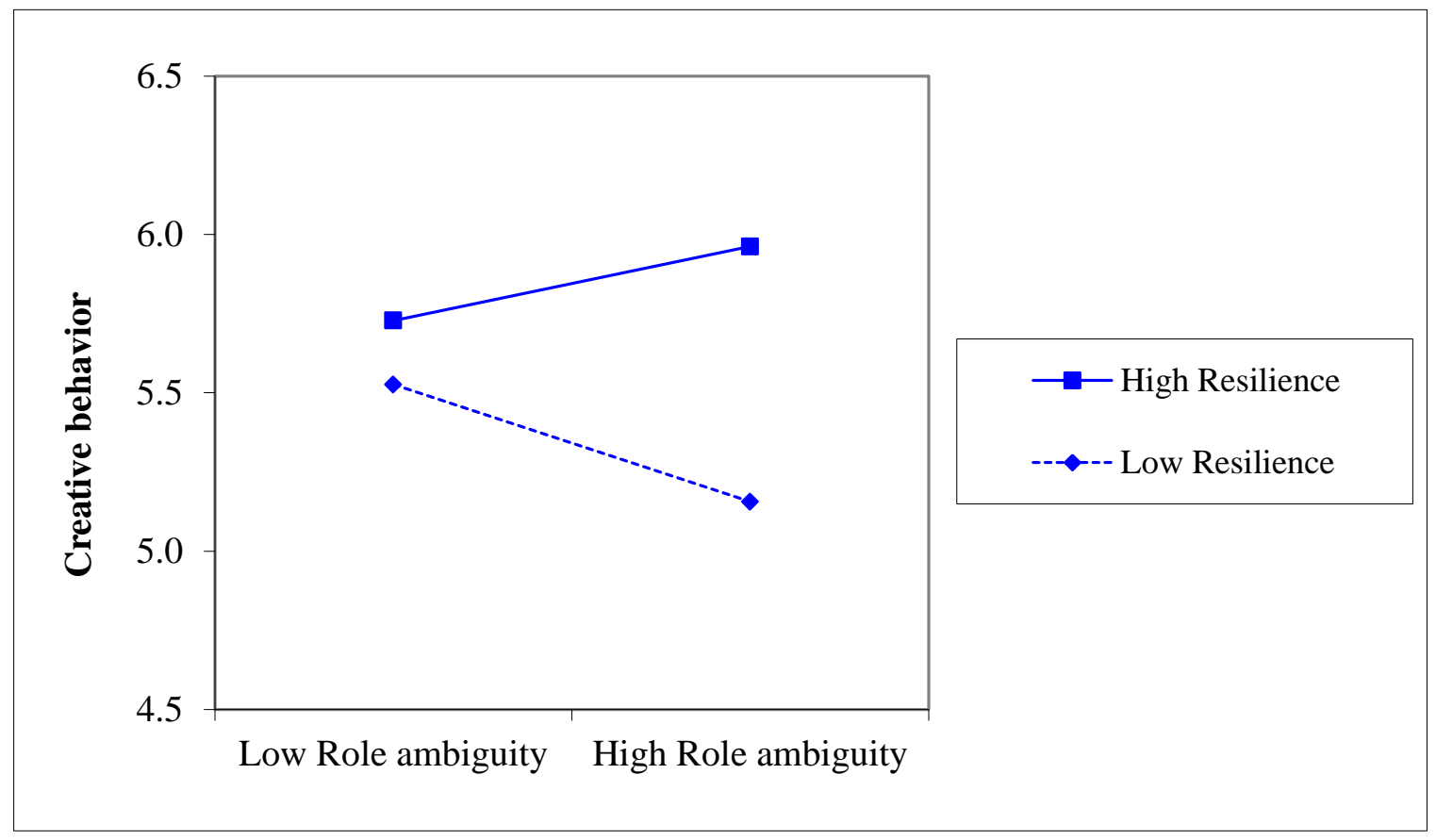


Figure 3. Moderating effect of task interdependence on the relationship between role ambiguity and creative behavior

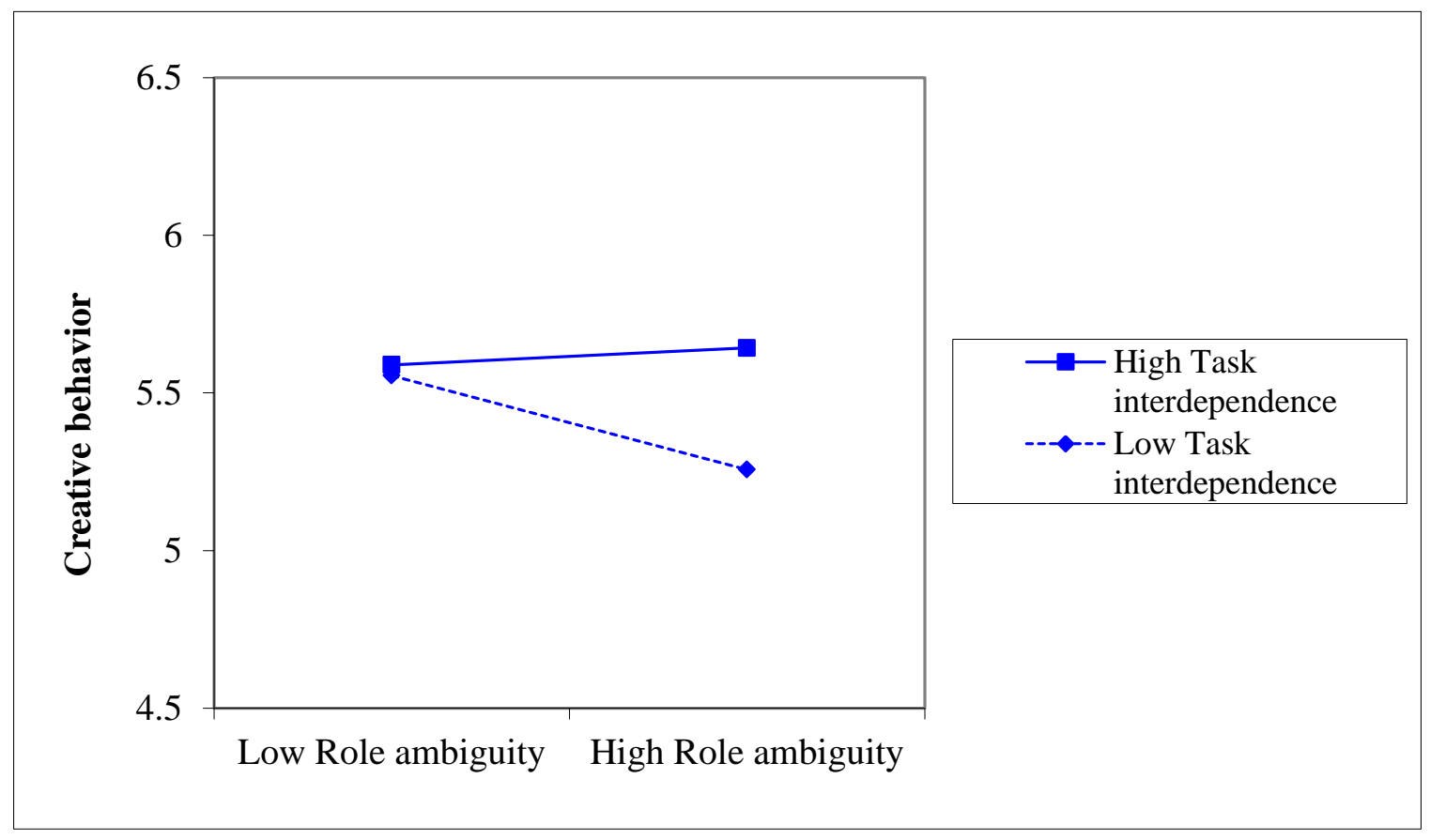


Figure 4. Moderating effect of emotion sharing on the relationship between role ambiguity and creative behavior

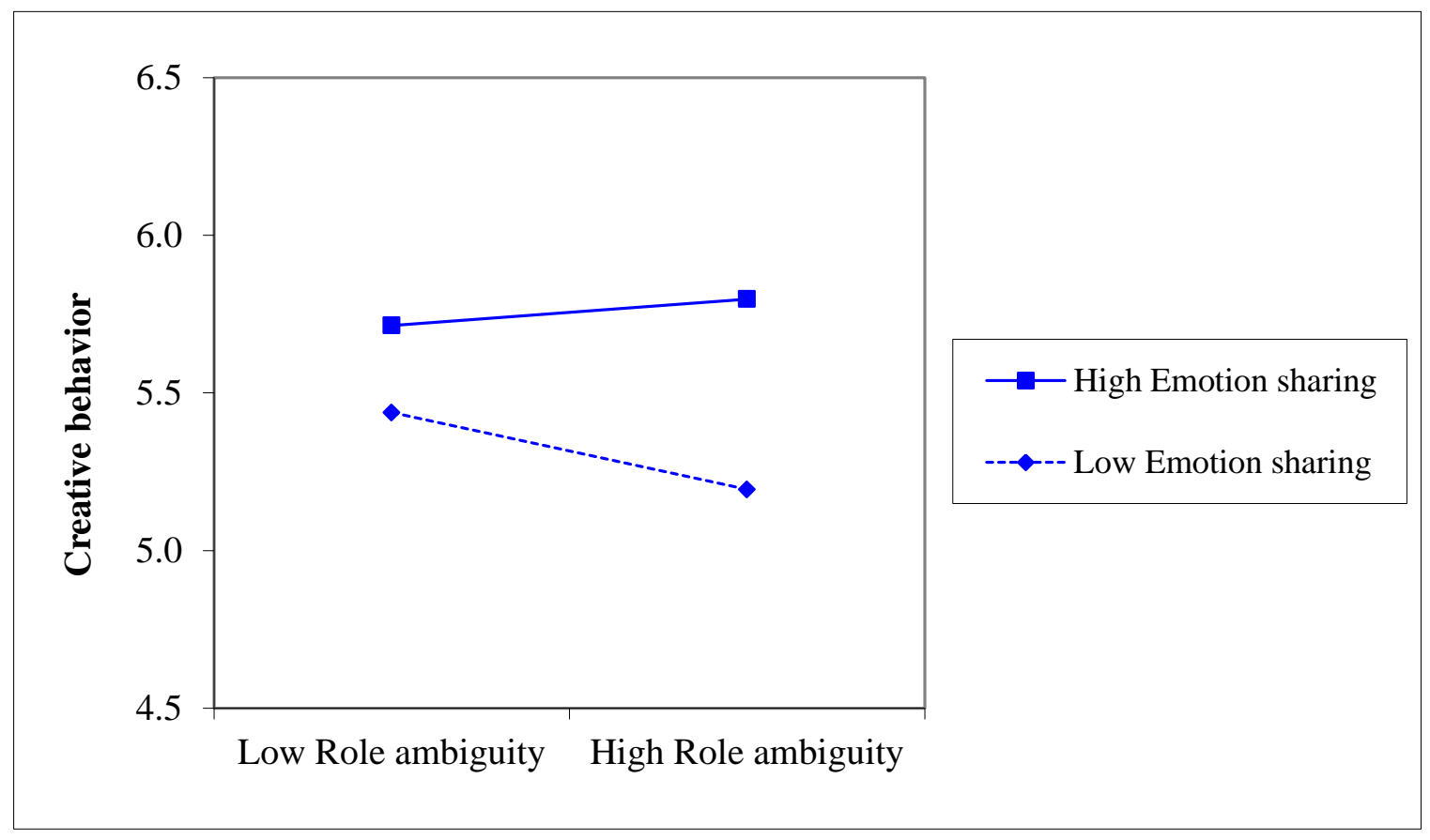


Table 1. Correlations and descriptive statistics

\begin{tabular}{|c|c|c|c|c|c|c|}
\hline & Mean & SD & 1 & 2 & 3 & 4 \\
\hline 1. Creative behavior & 5.451 & 1.293 & & & & \\
\hline 2. Role ambiguity & 3.146 & 1.431 & $-.449 * *$ & & & \\
\hline 3. Resilience & 5.596 & 1.113 & $.526 * *$ & $-.595 * *$ & & \\
\hline 4. Task interdependence & 4.511 & 1.510 & $.366 * *$ & $-.319 * *$ & $.341 * *$ & \\
\hline 5. Emotion sharing & 4.673 & 1.416 & $.500 * *$ & $-.516 * *$ & $.464 * *$ & $.418 * *$ \\
\hline
\end{tabular}

Notes: $\mathrm{N}=99$.

$* * p<.01 ; * p<.05$. 
Table 2. Regression results (dependent variable: creative behavior)

\begin{tabular}{|c|c|c|c|c|c|}
\hline & Model 1 & Model 2 & Model 3 & Model 4 & Model 5 \\
\hline $\mathrm{H}_{1}$ : Role ambiguity & $-.401 * * *$ & -.080 & -.034 & -.061 & -.040 \\
\hline Resilience & & $.357 * *$ & $.252 *$ & $.253+$ & $.304 *$ \\
\hline Task interdependence & & .105 & .038 & .105 & .089 \\
\hline Emotion sharing & & $.235^{*}$ & $.213^{*}$ & $.225^{*}$ & $.220 *$ \\
\hline $\mathrm{H}_{2}$ : Role ambiguity $\times$ Resilience & & & $.151 * *$ & & \\
\hline $\mathrm{H}_{3}$ : Role ambiguity $\times$ Task interdependence & & & & $.088^{*}$ & \\
\hline $\mathrm{H}_{4}$ : Role ambiguity $\times$ Emotion sharing & & & & & $.082 *$ \\
\hline $\mathrm{R}^{2}$ & .199 & .376 & .421 & .405 & .405 \\
\hline $\mathrm{R}^{2}$ change & & $.177 * * *$ & $.045 * *$ & $.029 *$ & $.029 *$ \\
\hline
\end{tabular}

Notes: $\mathrm{N}=99$; unstandardized coefficients (two-tailed $p$-values).

$*^{* *} p<.01 ; * p<.05 ;{ }^{+} p<.10$. 